\title{
Los niños de las campanas: \\ Testigos de un sujeto que habita el patrimonio visual y sonoro en los pueblos de Boyacó
}

Javier Ramos

\section{Resumen}

En este breve artículo de reflexión se narra el recorrido por algunos pueblos de Boyacá, Colombia, en aras de detectar la relación entre las capillas doctrineras, sus campanarios y el impacto cultural y social que estos generan. El análisis y las conclusiones se concentran, especialmente, en los jóvenes que tocan las campanas, su concepto del tiempo y los comportamientos derivados de este fenómeno.

Palabras clave: Boyacá, campanarios, colonia, Hispanoamérica, historia del arte, sonido

\section{Abstract}

This short paper of reflection recounts the journey through some villages of Boyacá, Colombia, in order to detect the relationship between the chapels doctrineras, their bell towers and the cultural and social impact they generate. The analysis and conclusions focus, in particular, on the young people who ring the bells, their concept of time and the behaviours derived from this phenomenon.

Keywords: America, art history, bell towers, Boyacá, colony, sound 


\section{La campana: un sujeto sonoro, nostálgico e histórico en Hispanoamérica}

En una gran cantidad de ciudades de Hispanoamérica, las configuraciones urbanísticas recibieron consejo de la religión católica (Arbeláez, 1964), con el beneplácito de la Corona española, a fin de que los templos y centros de culto se aseguraran una posición privilegiada en zonas neurálgicas y altamente pobladas. Todo esto medido al alcance de un golpe de campana.

Los campanarios fueron también hitos que atestiguaron la reducción de pueblos (Romero, 2008), poblaciones y formas de vivir muiscas. Si doblaban las campanas era claro que se habían erigido centros de culto católico, testigos y epicentro de todo un modo de conquista y dominación decantado al haber sido instituido y probado en otras regiones del Imperio como Nueva España o el Virreinato del Perú (Jaramillo, 1965).

La Nueva Granada, como sitio alejado de un control estricto por parte de la Corona a los encomenderos y escondido en su geografía impenetrable, permitía que los abusos a los conquistados y nuevos fieles católicos fueran constantes

\section{Sujeto cyborg histórico}

Dentro de los nuevos tipos de relaciones que se están gestando alrededor de la campana como sujeto sonoro, encontramos una que nos llama poderosamente la atención: la del sujeto cyborg (Simondon, 2008). La campana ha venido cambiando su presencia física debido a motivos económicos y prácticos, y aunque continuamos escuchando su repicar incansable, su fuente sonora análoga (resultado de su naturaleza como
(Sánchez, 2011). Las campanas significaron muchas veces el llamado al control poblacional muisca. Estos antiguos habitantes, en lugares como Boyacá y Cundinamarca, por ejemplo, debían reportarse en la plaza en horarios específicos so pena de sufrir quemas de sus bohíos, sanciones sociales o incluso encarcelamiento (Romero, 2008).

Hoy en día, las iglesias que se erigieron en su momento como centros de credo y poder se han mantenido en pie gracias a fuerzas que ya no son totalitarias (Gruzinski, 1995), hecho que, de manera simbólica, le permite a la campana redimirse de sus pecados eclesiásticos y levantar su voz como uno de los primeros objetos fenomenológicamente democráticos, de los creados por el hombre, para que su sonido sea capaz de llegar a todos los habitantes de estos centros urbanos sin distinción alguna. Esta relación, que ahora va más allá de la fe, nos invita a averiguar lo que ocurre en la actualidad con este vínculo entre la campana, el campanario y los habitantes de las zonas.

instrumento idiófono ${ }^{1}$ ) ha venido reduciéndose para dar paso a fuentes electrónicas como altavoces, bocinas y cornetas alimentadas eléctricamente y manejadas por sistemas de reproducción en formatos digitales: CD, MP3, etc. En muchos casos, estas grabaciones no corresponden a la realidad de la campana como objeto físico presente en el campanario, sino que, más bien, este nuevo sujeto cyborg imita sonidos de otros campanarios más celebres y lejanos. 
Nos preguntamos entonces ¿cómo este cambio de apariencia en el significante (sujeto visual) de la campana puede afectar la relación nostálgica que esta tiene con sus oyentes?, ¿se mantiene?, ¿cambia su significado o tiende a desaparecer?

\section{Sujeto nostálgico}

La nostalgia, al tratarse de una compleja emoción humana que aparentemente está ligada con emociones que pertenecen exclusivamente al pasado, mantiene una firme relación con el tiempo y el espacio, independientemente de la experiencia que estos proporcionen. La nostalgia puede ser fuente de múltiples experiencias que pueden ayudar a una comunidad a reforzar los lazos con su pasado y cambiar la visión que tiene sobre su presente y su futuro (Routledge, 2011). Averiguar los modos de comunicación de las campanas y la relación que la comunidad mantiene con ellas nos ayuda a entender la forma en que los habitantes circundan las iglesias en Latinoamérica y cómo se relacionan con su pasado. Como se verá, hablamos de un gesto

\section{Los niños de las campanas}

En el altiplano cundiboyacense, no muy lejos de Bogotá, la mayor metrópoli urbana, se ubicó el corazón del antiguo Nuevo Reino de Granada. Allí, entre accidentes montañosos, sobreviven y resisten culturalmente una serie de poblados que en otros tiempos fueron testigos vivos de procesos de adoctrinamiento en la fe católica.
Finalmente, este cambio puede rastrearse en la experiencia estética sonora que, en la actualidad, es impulsada por la campana y que utiliza a la nostalgia como detonante.

con un fuerte arraigo en lo colonial y lo local. En el altiplano cundiboyacense, el problema de estudio nos conduce a las capillas doctrineras en los pueblos de Cucaita, Tópaga y Oicatá. $\mathrm{Al}$ acercanos a sus inmediaciones, la presencia de las campanas en sus centros históricos se hace notoria y nos hace preguntarnos sobre su procedencia y sobre las historias que pueden estar atadas. Inmediatamente notamos que la solemnidad y aparente relación sagrada con su sonido y su mensaje es mediada por los niños de las veredas aledañas que con su naturaleza y alegría le dan un giro totalmente nuevo al trato sagrado que los habitantes suelen tener con las campanas y su sonido.

Este territorio, con un ancestral arraigo en la herencia del pueblo muisca, presenta en sus iglesias un especial apego a prácticas de tiempos coloniales en los que el manejo del tiempo y los quehaceres cotidianos aún están sincronizados con los tiempos eclesiásticos marcados por golpes de campana. 
Figura 1. Manera en la que naturalmente se sobrepone el antiguo territorio Muisca (en violeta) en los actuales departamentos de Cundinamarca y Boyacá en Colombia

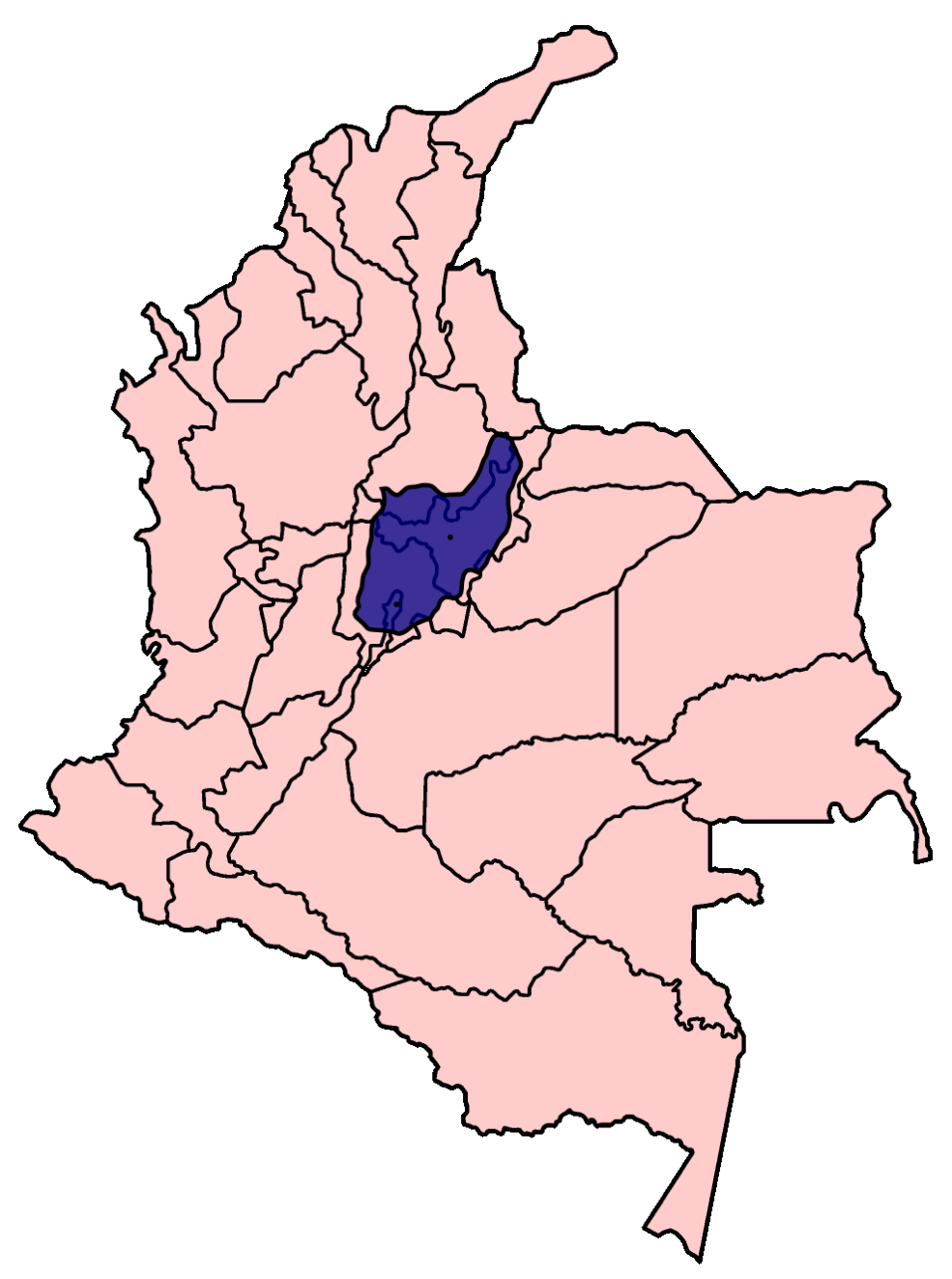

Fuente: Fibonacci (21 de octubre del 2006).

Esta sincronía, que se ejecuta a veces con el Ángelus y a veces con el reloj, fue el efectivo método que durante siglos emplearon la Corona española y su representación en forma de credo (la Iglesia católica) para coordinar con éxito las actividades de grupos sociales numerosos, en especial, cuando se requería que se reportaran en las plazas principales a determinadas horas con el objetivo de que se sincronizaran en sus actividades y en su fe (Romero, 2008).

Uno de los instrumentos que de manera efectiva logró el cometido de convocar fue la campana, en esencia, gracias a su ineludible y característico sonido. Este objeto, cuya invención y asociación a un grupo humano particular aún no han podido 
ser esclarecidas, fue traído por los artesanos del norte de España que se especializaron en su fabricación y que vinieron a los territorios ultramarinos en América para cumplir con encargos de nuevas iglesias en poblados previamente reducidos. La tarea de reducir a los indígenas en pueblos de mayor tamaño, que tenía como objetivo concentrar un gran número de habitantes en puntos específicos, surgió primeramente en Nueva España, lugar donde la Corona tenía como principio la conservación de los naturales bajo la religión cristiana.

Primeramente mandareis notificar al encomendero cuyo pueblo e yndios pretendieredes ajuntar y poblar que juntamente con vos se halle presente, y vos los susodichos y cada uno de vos en el pueblo que asi juntaredes, juntamente con el encomendero o religioso o saçerdote que doctrinare los dichos yndios, paseareis y vereis por vista de ojos el término del dicho pueblo y elegiréis y señalaréis la parte y lugar más conveniente para juntar los dichos yndios $\mathrm{y}$ hazer el dicho pueblo, procurando que el dicho sitio y lugar sea sano y enjuto y apartado de ciénagas y pantanos que suelen causar enfermedades, y que lo bañe el sol luego que saliere (Romero, 2008, p. 173).

Así, en cada poblado que iba siendo motivo de reducción se encargaba la fabricación de varias

\section{El oficio de campanero}

La tradición de fabricación de campanas siguió una línea que llegó hasta el reino de Castilla y Aragón, proveniente de los Países Bajos (Brox y Orive, 1985). En aquellos tiempos era un oficio de gran valor y utilidad para divulgar la presencia de Dios en la cotidianeidad de ciudades, pueblos y aldeas. Poco a poco, la tarea de fabricación se campanas, ya que la Corona y su representante en el altiplano cundiboyacense contrataba la construcción de las iglesias a un mismo maestro de obra: "en la inmensa mayoría de los casos los maestros de obra $u$ oficiales encargados de construir las iglesias doctrineras del Nuevo Reino de Granada percibían su salario por el sistema de tercios" (Romero, 2008, p. 165). Bajo este sistema, el maestro de obra asumía el encargo de construir un puñado de iglesias acoplando un plano original a diferentes poblados y procurando utilizar los mismos artesanos para minimizar la cantidad de encargos que debía adjudicar.

Así, las campanas eran emplazadas en lo alto de las espadañas de cada pueblo del altiplano para dirigir y ser espectadoras de los procesos de adoctrinamiento y control.

Ytem, junto a la dicha yglesia y casa del dicho religioso daréis gorden como se haga una casa e portal que aya de servir y sirva de escuela donde los niños se junten a ser enseñados y dotrinados y a les mostrar a las demás cosas como es leer y escribir, y apartados deste aposento otro donde alguas yndias christianas y de buena vida y exemplo tenga las niñas recogidas y les enseñen la dotrina y otras cosas que sean neçesarias enseñarles, y el saçerdote o religioso las visite y enseña, espeçialmente a las yndias mayores que an de ser maestras de las niñas. (Romero, 2008, p. 175)

unió con la tradición de los campaneros que hacían sonar las campanas para mejorar la calidad de las interpretaciones y la durabilidad de las aleaciones utilizadas para ellas (Hibbert, 2008).

En la Nueva Granada, al igual que en los otros territorios coloniales de España, la composición 
social de los migrantes impedía que familias enteras se trasladaran a los nuevos territorios considerados tradicionalmente como fuentes de lucro rápido, pero, por otro lado, catalogados como inhóspitos y peligrosos. Así, las familias de campaneros y fabricantes de campanas enlazadas entre sí en el territorio continental europeo tuvieron una tarea difícil para asentarse y prosperar a través de su oficio en América.

En el altiplano cundiboyacense, territorio en donde se llevó a cabo una conquista feroz que causó gran desplazamiento, la población se vio bastante diezmada por la mano dura de la Corona. Los campaneros, que habitaban principalmente en lo que hoy serían Asturias y Extremadura, no fueron traídos directamente para que materializaran su saber sonoro en las nuevas tierras debido al poco atractivo y la incertidumbre que tal desplazamiento significaba para ellos (Brox y Orive, 1985). Asî pues, en lugar de los campaneros, los fabricantes de campanas y los sacerdotes transmitieron las secuencias de interpretación de las ceremonias religiosas. De modo que detalles como la notación, el ritmo y la armonía se vieron reinterpretados por sacristanes y acólitos que no recibieron una instrucción adecuada, ya que simplemente fueron nuevos actores que no pertenecían directamente al círculo de saberes de los antiguos campaneros.

Así, el antiguo oficio de la fabricación de campanas y la interpretación de melodías en lo alto de los campanarios de la Nueva Granada tuvo un cambio forzado en sus funciones y en las personas encargadas de los llamados a misa. En consecuencia, esto alteró el ritmo de las actividades de cada pueblo, cuya responsabilidad pasó a manos de los sacristanes y acólitos que, en cualquier caso, no superaban los trece o catorce años de edad.

Estos niños (varones) ayudaban con los oficios de la iglesia por requerimiento de sus familias para estar más cerca de la fuente de poder en el pueblo: el sacerdote. Llevaban vidas sencillas de obediencia y utilizaron gran parte de su tiempo para ayudar a realizar las colectas, realizar actividades de apoyo general y de oficios varios que los sacerdotes, por su edad y jerarquía social, no realizaban gustosamente.

Estos niños se convirtieron en el común denominador del oficio de campanero en el altiplano cundiboyacense. En pueblos como Tópaga, Cucaita y Oicatá se concentraban grupos de preadolescentes que se paseaban con letargo frente a sus iglesias y plazas mayores. Cada uno tenía una historia particular y una relación con el sacerdote de turno muy diferente a la de sus homólogos; sin embargo, aquello que los unía era el dominio sobre el tiempo y sobre los quehaceres de convocatoria dentro de las iglesias. En esencia, ellos fueron los encargados de una labor que puede ser una de las más importantes de la vida social en estos territorios: tomar y regular el pulso de vida de toda la comunidad.

del cambio de mando y de regencia en estas tierras en los últimos siglos son los campanarios y las campanas de las capillas doctrineras que sirvieron como sustento para este estudio. especialmente benévolo con las poblaciones del altiplano cundiboyacense. Estos testigos

\section{El manejo del tiempo}

En lo alto de cada campanario se encuentran testigos vivos de un pasado colonial que no fue 
Cada capilla era una copia implementada y acondicionada a cada terreno con un pago único a un mismo arquitecto constructor (Romero, 2008) $\mathrm{y}$, aunque hasta este momento no podemos atar claramente la relación de autoría que las une, es evidente, por su configuración, que todas tenían un mismo génesis y un mismo destino como capillas doctrineras.

Las espadañas terminadas en pináculos son un sello clásico de la arquitectura de la Corona en tiempos de la Colonia. Estas permitían un acceso exterior a las campanas desde largas cuerdas que iban hasta los espacios internos de las iglesias. Esta facilidad y sencillez arquitectónica también facilitó el empoderamiento y la apropiación del oficio de los niños campaneros, pues no requerían de ningún entrenamiento especial para acceder y utilizar las sogas que colgaban de cada campana. Como lo señala uno de ellos: "a mí el mismo día que me enseñaron, ese día ya las toqué [...]. Son solo dos canciones, para funeral es una y para misa es otra" (Niños campaneros de Cucaita, 16 de febrero del 2016).

Figura 2. Arriba: fotografía de los niños acólitos vendiendo obleas para el mantenimiento de la iglesia en la plaza de Cucaita, Boyacá. Abajo: espadaña de la iglesia de Cucaita y niños campaneros en el espacio interior de la iglesia aledaño a la espadaña
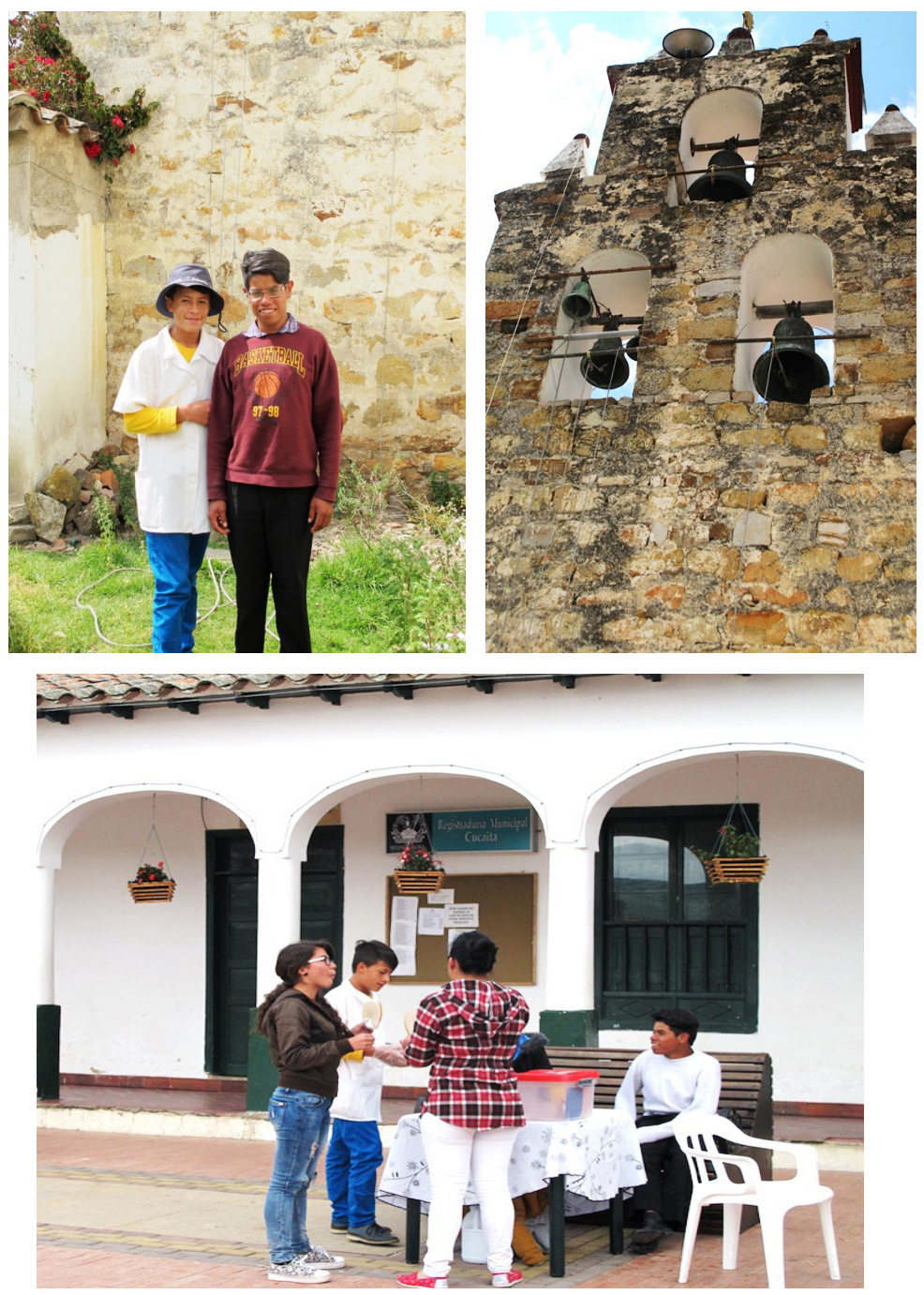

Fuente: archivo personal del investigador (2016). 
La manera como los niños campaneros han aprendido a interpretarlas no hace parte de un entrenamiento con pasos y ejercicios claros, ni ha tenido como objetivo la transmisión del conocimiento de los campaneros en tierras peninsulares a sus iguales en tierras americanas; por el contrario, su interpretación se da de manera casi empírica y apela a la relación sonora de alta recordación que ya existía en cada niño respecto a las diferencias en los toques de campana: "aquí las tocamos entre los acólitos [...] pero es el padre o el seminarista el que enseña cómo se tocan" (Niños campaneros de Tópaga, 1 de julio del 2016).

Figura 3. Iglesia de Tópaga. En la parte superior izquierda: el pináculo y el campanario de la iglesia de la Inmaculada Concepción. En la parte superior derecha: la entrada lateral al campanario en el que la niña sacristana abre la puerta y permite que el niño campanero ingrese para tocar el llamado a misa de 6:00 pm. En la parte inferior: secuencia del toque de campanas (el niño campanero cuelga de una soga y de otra para hacer sonar las campanas)
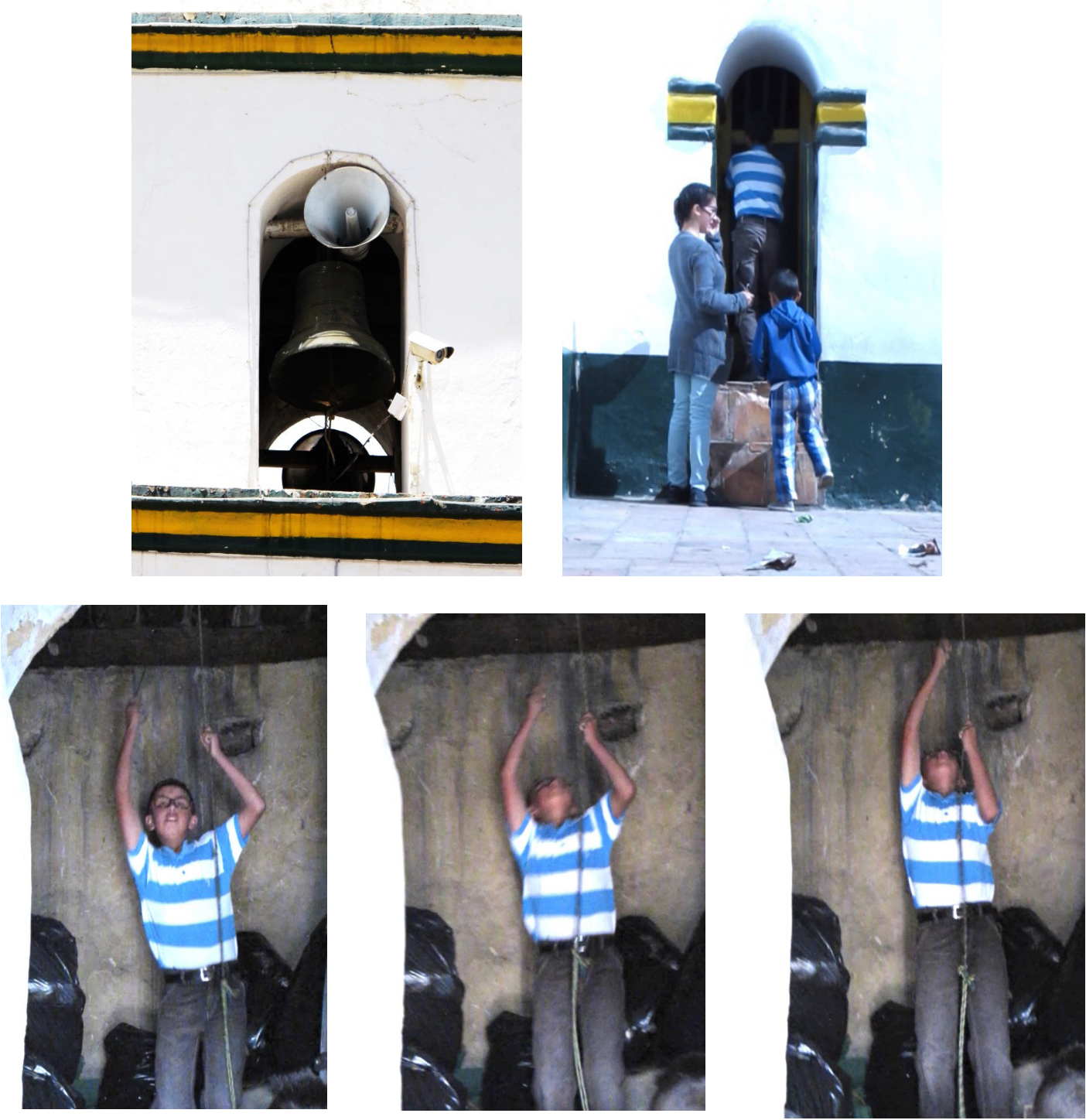

Fuente: archivo personal del investigador (2016). 
Figura 4. Arriba: campanario de la iglesia doctrinera de Cucaita y niño campanero. Abajo: secuencia visual del toque de campanas del niño campanero de la iglesia de Cucaita. Dos campanas con sogas que caen desde la parte baja de una espadaña y que terminan en un espacio interior aledaño al coro
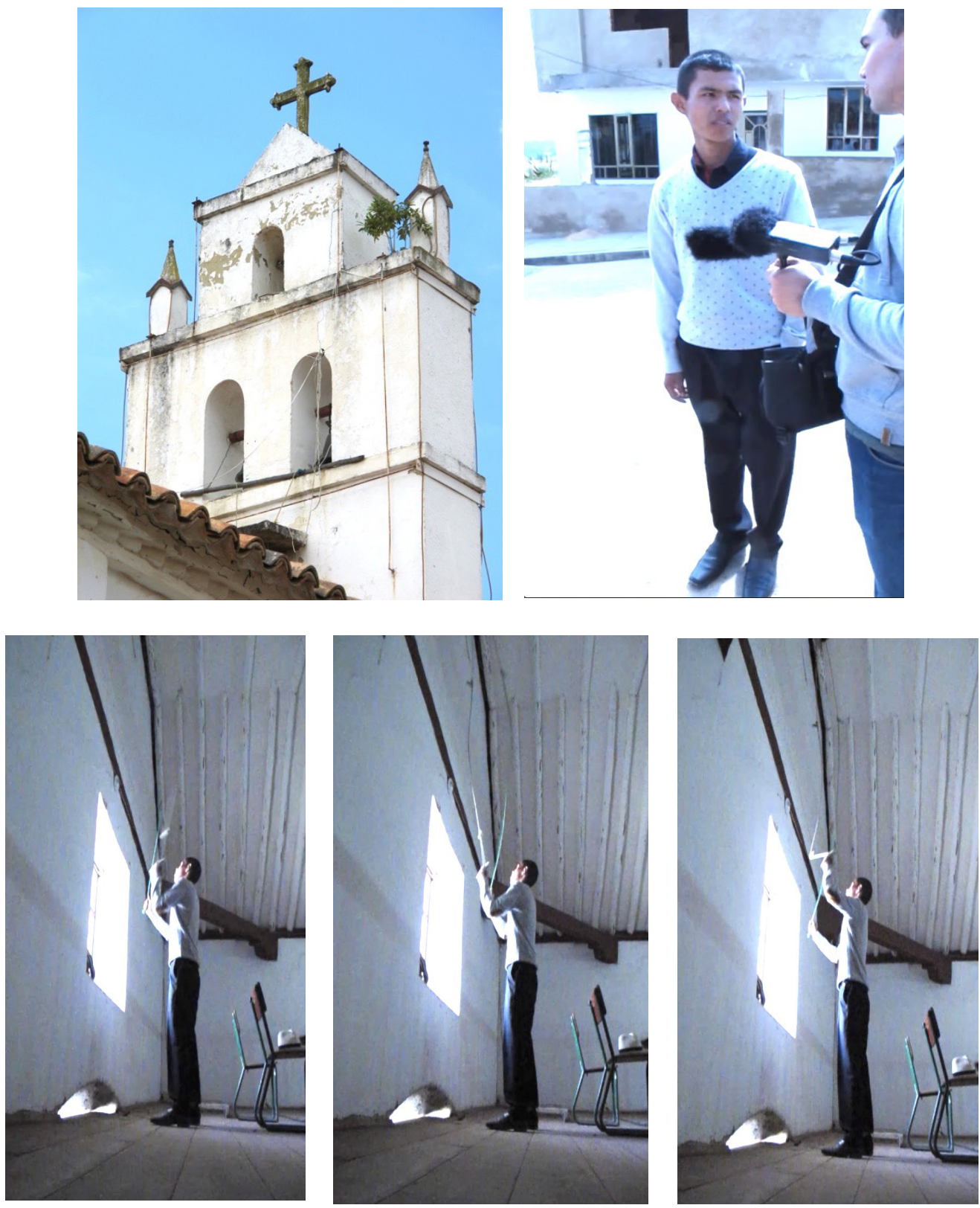

Fuente: archivo personal del investigador (2016).

\section{El artesano: sujeto creador de sujetos}

A partir de la definición del sujeto que controla el tiempo -identificado en este caso en cada uno de los niños asociados a las iglesias doctrineras visitadas-, es preciso hablar ahora de la procedencia de las campanas, que datan de tiempos de la Colonia. Sin embargo, el tratamiento dado a este recorrido se aparta de la historia que teje a los regentes de las iglesias 
y a sus acólitos campaneros, para trasladarse al relato vivo de uno de sus artesanos creadores.

En inmediaciones de Bogotá, a unos 250 kilómetros, está la población de Nobsa. Allí se encuentra el taller de un artesano agricultor hacedor de campanas. Su oficio data de seis generaciones de artesanos de las que él es el último heredero y sin ningún sucesor a la vista. Él, junto a otros dos o tres artesanos en toda Colombia, guardan los secretos de un oficio que en otros tiempos supo proveer de campanas a todas las iglesias del Nuevo Reino de Granada. Él es Saúl Tristancho y su definición como agricultor tiene la misma fuerza dentro de su identidad como la tiene su línea sanguínea que lo conecta directamente con una serie de artesanos que, en los tiempos de Juan de Gauss, vinieron desde el norte del Reino de España a abastecer de sujetos sonoros a un nuevo conglomerado de fieles que esperaban obtener una comunicación más directa con un Dios que para las comunidades indígenas era desconocido.

Figura 5. Saúl Tristancho. Artesano de la campana en el portal de su taller

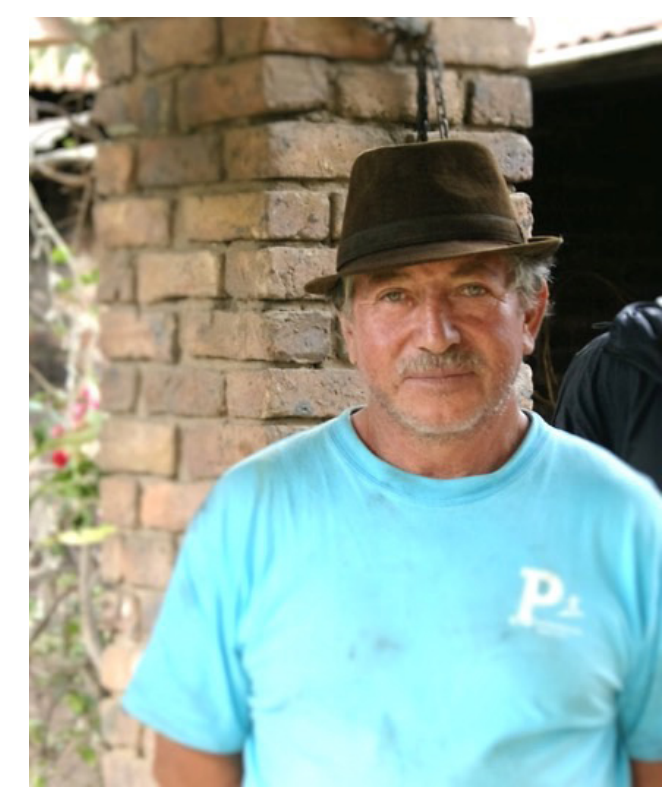

Fuente: archivo personal del investigador (2016).

\section{Destino: el nacimiento de un sujeto}

La presencia cada vez más escasa de campanas que repiquen en lo alto de las centenarias doctrineras en Boyacá nos ha hecho recorrer varios kilómetros hasta Nobsa. Este municipio cuenta con varios caminos que conducen a pequeñas y retiradas veredas asentadas en el regazo de grandes montañas.
Como se dijo más atrás, la campana lleva consigo una tradición artesanal que no ha podido ser rastreada fielmente hasta sus orígenes. Se trata de uno de esos oficios que parece haber nacido con el hombre y que se encuentra presente en la historia de cada antigua civilización. Encontrarnos frente a frente con uno de los dos únicos artesanos en el 
altiplano cundiboyacense que mantienen viva la tradición antiquísima de fabricar campanas bajo la técnica de cera perdida, nos permitió tener la excusa perfecta para hablar de sonido, de sujeto y de patrimonio. Esta visita y su conclusión hacen parte de un estudio mucho más ambicioso que pretende entender las dinámicas sociales y sonoras que envuelven el uso y el desuso de los campanarios de las iglesias en los asentamientos urbanos en Latinoamérica. La tradición de su oficio no tiene que ver con algo único en este país o con la relación que mantuvo con España

\section{El artesano, la campana, los niños}

Tras haber recorrido las iglesias doctrineras y después de haber tenido la oportunidad de observar las dinámicas en torno a la campana (por ejemplo, cuándo se toca y se fabrica), se pudo observar, con sorpresa, una escala en la que son los niños, y no los sacerdotes o los artesanos, los que definen las dinámicas temporales en los pueblos de Boyacá.

Si bien es cierto que Saúl Tristancho, artesano de la campana, cuenta con más de cincuenta años de experiencia y seis generaciones de artesanos fabricantes sobre sus hombros, no es él quien finalmente detona el sonido ni quien, en últimas, ejerce como influenciador y máximo exponente del fenómeno sonoro (Tristancho, 28 de julio del 2016). Don Saúl, a pesar de tener cada campana en su taller durante un periodo de dos o tres meses, nunca llega a conocer el repicar de su sonido; para él, su presencia se basa exclusivamente en su correcto contorno y peso según el manual. Él entrega sus encargos en su taller; el recibo de compra siempre detalla la cantidad de kilos finales de la campana, pero nunca su nota o correcto sonido. al haber hecho parte de su imperio colonial; más bien, tiene que ver con la búsqueda del origen del tiempo, de la religión y de la arquitectura.

Los campanarios de iglesia han estado ahí durante siglos resguardando las campanas que regían los horarios, convocaban a un culto común y nos permitían identificarnos con una comunidad en particular. Es hora de mirar hacia arriba e intentar ver qué está pasando con sus campanas antes de que desaparezcan por completo.

Por otro lado, los sacerdotes retienen la campana en sus manos y la custodian por un tiempo muy corto. Cuando un artesano como Saúl Tristancho entrega una campana y la coloca en lo alto de una iglesia, el sacerdote regente la ubica rápidamente y la bendice para inmediatamente librarse de la responsabilidad de tocarla y entregar esta responsabilidad a sus acólitos y sacristanes.

En este punto, los niños campaneros muestran nuevamente cómo ejercen su control y poder sobre el tiempo y los quehaceres en estos pueblos, ya que son ellos los que, en última instancia, tienen el dominio de la campana y los que corrigen, mejoran y regulan los tiempos y armonías de las campanas en el campanario. Estos regulan, de paso, el pulso de toda una cultura, una que para poder sobrevivir depende de esta unión entre la solemnidad de lo antiguo y la fogosidad de la juventud.

Niña sacristana: ¡Oiga!, ¡la tocó mal!

Niño Campanero: ¡No importa!, nadie se da cuenta... 


\section{Referencias}

Arbeláez, C. (1964). Templos doctrineros y capillas posas en la Nueva Granada. Revista Universidad Pontificia Bolivariana, 31(108), 184-203. Recuperado de https:/ / bit.ly/36e0AR5

Brox, L. y Orive, M. (Productores) y Brox, L. (Dir.). (1985). Elaboración tradicional de campanas [Película]. España: La Rioja.

Fibonacci, O. (21 de octubre del 2006). Ubicación de la confederación muisca en el mapa de la República de Colombia [recurso en línea]. Recuperado de https://bit.ly/38cDQTA

Gruzinski, S. (1995). La colonización de lo imaginario. Sociedades indígenas y occidentalizacion en el México español. Siglos XVI-XVIII. México D. F.: Fondo de Cultura Económica.

Hibbert, W. (2008). The Quantification of Strike Pitch and Pitch Shifts in Church Bells (tesis de doctorado). Milton Keynes Open University, Londres, Reino Unido.

Jaramillo, J. (1965). Mestizaje y diferenciación social en el Nuevo Reino de Granada. Anuario Colombiano de Historia Social y de la Cultura, 3, 21-48. Recuperado de https://bit. ly/38mZu7M

Niños campaneros de Cucaita. (16 de febrero del 2016). Entrevista a los niños campaneros que venden obleas en la plaza de Cucaita, Boyacá, Colombia. Entrevista con J. Ramos y E. Cote [archivo personal del investigador].

Niño campanero de Oicatá. (16 de febrero del 2016). Entrevista con el niño campanero de la iglesia de Oicatá, Boyacá, Colombia. Entrevista con J. Ramos y E. Cote [archivo personal del investigador].

Niños campaneros de Tópaga. (1 de julio del 2016). Entrevista con el niño de las campanas de Tópaga, Boyacá, Colombia. Entrevista con J. Ramos y E. Cote [archivo personal del investigador].

Romero, G. (2008). Los pueblos de indios en nueva granada: trazas urbanas e iglesias doctrineras (tesis de doctorado). Universidad de Granada, España. Recuperado de https://bit. ly/2Yy9czL

Routledge, C. (2011). The Past Makes the Present Meaningful: Nostalgia as an Existential Resource. Journal of Personality and Social Psychology, 101(3), 638-652. Recuperado de https://bit.ly/2s6Wuvl 
Sánchez, E. (2011). Codazzi, la Comisión Corográfica y la construcción de nación. Unimedios: un Periódico. Recuperado de https:// bit.ly/34X9pyz

Simondon, G. (2008). El modo de existencia de los objetos técnicos. Buenos Aires: Prometeo.

Tristancho, S. (28 de julio de 2016). Entrevista con Saúl Tristancho, artesano de la campana, Nobsa, Boyacá, Colombia. Entrevista con J. Ramos y E. Cote [archivo personal del investigador]. 